\title{
A case for teaching English as a service subject at universities in Kenya
}

\author{
Angelina Nduku Kioko
}

\begin{abstract}
Language plays an important role in teaching and learning activities whether the teachers and learners are conscious or unconscious of this. Thus language and communication are the most important components of the school curriculum (Lopez, 2000, p.1). This is because there is a very close relationship between language and thought. As Muthwii (2002, p. 1) notes, “special problems arise in multilingual communities where learners frequently join the school system equipped with home languages that are often different from the languages of education". A consequence of this is that the learner is expected to acquire and utilize skills using a language he or she is not quite proficient in. It is, however, usually expected that by the time students join university they have enough of the language of instruction to function effectively in their major areas of study and to interact with the acquisition and propagation of knowledge at that level. Recent studies on learner English have, however, shown that the language of high school graduates, (Nyamasyo, 1992) and even that of university students (Njoroge, 1996) have the same type of errors as those observed in the English of learners at lower levels of education. If many students entering the universities today have not attained the expected English level, what should be done to counter this challenge?
\end{abstract}

Using an analysis of students' performance in an English Placement Test, this paper discusses the English language needs of Kenyan students at the time of entry to the university; appraises the programs which are put in place to address this need in the local universities; and makes recommendations on what universities in Kenya ought to be doing in order to produce students that can compete internationally and fit in the global academic field.

\section{The 'Foreign' Media of Instruction}

Why do we have a 'foreign' language medium of instruction in most Third world countries? This question has been the subject of debate for many decades and despite the many resolutions agreed upon in many national and international forums to promote indigenous languages for use as media of instruction, the practice has continued to be the use of a 'foreign' language even as early as lower primary. Most of the times we have sought the answer to this question in our colonial past: that the colonial masters brought modern education wrapped in their mother-tongues and colonized our minds to such an extent that we have been unable to separate the two. 
100 Angelina Nduku Kioko

Other frequently quoted reasons for retaining a foreign medium are socioeconomic in nature; that even when we have seen the need to adopt the indigenous languages as languages of instruction in our educational systems, this ideal gets challenged by the cost of training teachers, production of textbooks and other relevant teaching and learning materials in the various languages represented in our multilingual and multicultural nations. Thus many of the multilingual African states have come up with policy statements that are in line with national identities and pride, but the implementation of these policies is delayed by socio-political and economic challenges.

Without downplaying the significance of the two reasons given above, I think one of the main reasons why the languages of the former colonial masters have continued to take center stage in education is that these languages give our learners opportunities to participate in higher education nationally, regionally, and internationally. As Moyo says, "the choice of media, particularly beyond secondary school level, is not dependent on a community's wishes, but rather dictated by global academic pursuits"(Moyo, 2002, p.149). We want the graduates of our educational systems to find relevance beyond our ethnic, national and regional boundaries.

\section{Studies on Media of Instruction}

Recent studies on language policy and education have continued to emphasize the significance of the learners' first language as the language of instruction ( Lopez, 2000; Seepe, (2002); Moyo, (2002); Muthwii (2002); King'ei, (2002); Banda, (2003), but the bulk of the researches on the English medium in Kenya fall under second language acquisition studies and error analysis. These studies focus on establishing the learning / teaching strategies at the various levels in the educational system and examining the various difficulties learners at various stages face with the use of the various structures of the English language. Studies of this nature include (Njoroge, 1987, Nyamasyo, 1992, Njoroge, 1996). These studies generally establish, that even at the point of entry to the university, many Kenyan learners have not acquired the required proficiency.

Recent studies have begun focusing on the challenges facing the English media and calling for the recognition and description of a variety of English that is adapted to express the local meanings of the users as the Nigerian writer once said:

I feel that the English language will be able to carry the weight of my African experience ... But it will have to be a new English, still in communion with its ancestral home but altered to suit its new African surroundings. (Achebe, 1975, p.62)

Studies calling for the recognition and therefore description of a localized Standard of English include; Schmied, (1991); Kioko and Muthwii (2001); Muthwii and Kioko (2002); and Kembo-Sure, (2003). 


\section{The Falling Standards}

Though there has been an outcry that the standard of English is falling and the error analysis studies have shown the characteristics of the learners' interlanguage at various levels in the educational system, most of the recommendations in these studies turn back to high school and give recommendations on what can be done at that level. Of those that I have looked at, none apportions the burden to the institutions of higher learning, despite the fact that studies have established that learners at this level have difficulties similar to those experienced at earlier levels.

This paper uses an analysis of students' performance in an English Placement Test, to discuss the English language needs of Kenyan students at the time of entry to the university; appraise the programs which are put in place to address this need in the local universities; and make recommendations on what universities in Kenya ought to be doing in order to prepare students that can compete internationally and fit in the global academic field of e-learning.

\section{Description of the English Placement structure}

The placement examination used for this study is made up of three sections. Section A tests reading and comprehension. After reading the passage the candidates are required to answer ten objective questions that cover the areas of knowledge, comprehension, application, analysis, synthesis and evaluation. This section is awarded $20 \%$ of the grade. Section B, which is made up of two parts, tests grammar and usage. Part one, with 20 items, tests the various grammar skills and carries $40 \%$ of the grade. The second part of this section focuses on the meaning of words and phrases. It has 10 items and carries $20 \%$ of the total grade. Section $C$ requires the candidates to write a composition of about 500 words on a topic selected from two options. This section attracts $20 \%$ of the total grade.

The English placement examination is given to all undergraduate students who accept admission to the institution. The purpose of this examination is to determine the language needs of the first years so that an English remedial course can be provided to those whose language level is found wanting.

The examination is given during the orientation week and is marked promptly so that the results are available before the students finalize with the registration process. 
This examination is team marked by all the lecturers teaching English in the university.

\section{The Analysis}

The scores used in this paper are mainly based on one English placement test administered to 343 students in September, 2002 but just for comparison purposes, the general performance of the September, 2003 group of 240 students is presented.

\section{A: High school English Grades and English Placement Test Scores}

The first step in the analysis was to examine the high school English grades of the group. These are presented in table 1 below.

Table 1: Distribution of High School English grades in the 2002 Group

\begin{tabular}{|l|l|l|l|l|l|l|l|l|l|l|}
\hline GRADE & A, A- & B+ & B & B- & C+ & C & C- & D+, D,D- & E & Total \\
\hline No. & 17 & 49 & 84 & 75 & 41 & 45 & 17 & 11 & 4 & 343 \\
\hline$\%$ & $5 \%$ & $14.3 \%$ & $24.5 \%$ & $22 \%$ & $12 \%$ & $13 \%$ & $5 \%$ & $3 \%$ & $1.2 \%$ & $100 \%$ \\
\hline
\end{tabular}

This table shows that of the students admitted to the university, $77.5 \%$, had grade $\mathrm{C}+$ and above in English. It is usually expected that this group has the language skills that would enable them to go through university education with an English medium of instruction.

The second step was to take the 133 (39\% of the total population) students who failed the placement test and look at their high school English scores. Table 2 below maps the

Table 2: English Placement Scores below 60\% Compared to High School (KSCE) Grades (2002)

\begin{tabular}{|l|l|l|l|l|l|l|l|l|l|}
\hline High School grade & A, A-(17) & B+(49) & B(84) & B-(75) & C+(41) & C(45) & C-(17) & D+, D,D- (11) & E(4) \\
\hline Placement Failures & 2 & 6 & 31 & 32 & 23 & 20 & 11 & 7 & 1 \\
\hline Percentage that failed & $12 \%$ & $12 \%$ & $37 \%$ & $43 \%$ & $56 \%$ & $44 \%$ & $65 \%$ & $64 \%$ & $25 \%$ \\
\hline
\end{tabular}

2 out of the 17 students with A/A- in English at High School, scored below 60\% in the placement test. Though the proportions of failure for students with high school English grade C and below are quite high (C 44\%, C- 65\% and D 64\%), the total picture shows that of the 133 failures, 94 (70\%) of them had high school English scores of $\mathrm{C}+$ and above. Thus 94 out of the total 266 students who had high school English scores of $\mathrm{C}+$ and above, failed the English placement test and 39 out of the 77 students with below $\mathrm{C}+$ in High School English failed the placement examination.

Table 3: Distribution of High School grades in the sample (2003) 
Angelina Nduku Kioko 103

\begin{tabular}{|l|l|l|l|l|l|l|l|l|l|l|}
\hline GRADE & A, A- & B+ & B & B- & C+ & C & C- & D+, D,D- & E & Total \\
\hline No. & 38 & 21 & 67 & 44 & 25 & 33 & 6 & 5 & 1 & 240 \\
\hline$\%$ & $16 \%$ & $9 \%$ & $28 \%$ & $18 \%$ & $10 \%$ & $14 \%$ & $3 \%$ & $2 \%$ & $0.4 \%$ & $100 \%$ \\
\hline
\end{tabular}

Again in this group the majority of the high school scores, 175 out of 240 (73\%) fall above $\mathrm{C}+$.

Table 4: English Placement Scores below 60\% Compared to High school English grades (2003)

\begin{tabular}{|l|l|l|l|l|l|l|l|l|l|}
\hline High School Grade & A, A-(38) & B+(21) & B(67) & B-(44) & C+(25) & C(33) & C-(6) & D+, D,D- (5) & E(1) \\
\hline Placement failures & 13 & 2 & 19 & 10 & 12 & 15 & 5 & 4 & 1 \\
\hline Percentage that failed & $34 \%$ & $10 \%$ & $28 \%$ & $23 \%$ & $48 \%$ & $45 \%$ & $83 \%$ & $80 \%$ & $100 \%$ \\
\hline
\end{tabular}

$81(34 \%)$ of the total group that did the placement test in 2003) failed. Though the high proportions of failures again fall at the level of C and below (C 45\%, C- 83\% and D $80 \%)$, 56 out of $81(69 \%)$ of the failures had C+ and above in High School English. Out of the total 175 students with $\mathrm{C}+$ and above in High School English 56 (32\%) failed the placement test, while 25 (71\%) of the total 35 students with C and below in High School English failed the placement test.

What does this say about high school English grades and admission to the university? To begin with, this comparison clearly shows that candidates with English scores below $\mathrm{C}+$ have lower chances of getting university admission and the juxtaposition of the high school English scores and the English placement results (Table 2 and 4 ) shows that the probability of failing the English placement test increases as we go down the high school English grades: in $200251 \%$ of those with grade $\mathrm{C}$ and below failed while in $200371 \%$ of the same group failed. Thus it is possible for the admissions section in universities offering English placement tests to predict the size of the remedial English class by looking at the high school English scores.

\section{B: Performance in the Various English Skills}

Below (Table 5) I present a summary of the performance in the various English skills of a sample of 130 students drawn from the 2002 group. 
Table 5a: Distribution of English placement grades in the various skills

\begin{tabular}{|l|c|c|c|c|c|}
\hline Skill & Composition & Comprehension. & Grammar & Vocabulary & Total \\
\hline A & 10 & 10 & 4 & 1 & 25 \\
\hline B & 43 & 20 & 14 & 6 & 83 \\
\hline C & 52 & 34 & 56 & 15 & 157 \\
\hline D and below & 25 & 66 & 56 & 108 & 255 \\
\hline Total & 130 & 130 & 130 & 130 & 520 \\
\hline
\end{tabular}

Table 5b: Percentage scores

\begin{tabular}{|l|l|l|l|l|l|}
\hline Skill & Composition & Comprehension. & Grammar & Vocabulary & Total \\
\hline A & $7.7 \%$ & $7.7 \%$ & $3 \%$ & $0.7 \%$ & $4.8 \%$ \\
\hline B & $33 \%$ & $15 \%$ & $10.8 \%$ & $4.6 \%$ & $16 \%$ \\
\hline C & $40 \%$ & $26 \%$ & $43 \%$ & $11.5 \%$ & $30 \%$ \\
\hline D and below & $19.2 \%$ & $50.8 \%$ & $43 \%$ & $83 \%$ & $49 \%$ \\
\hline Total & $100 \%$ & $100 \%$ & $100 \%$ & $100 \%$ & $100 \%$ \\
\hline
\end{tabular}

Tables $5 \mathrm{a}$ and $5 \mathrm{~b}$ show that in nearly all the language skills the bulk of the students fall below the pass mark; $66(50.8 \%)$ in comprehension, $56(43 \%)$ in grammar, and $108(83 \%)$ in vocabulary. In Grammar $86 \%$ of the scores are below B, in comprehension $77 \%$, in Composition 59\% and in Vocabulary 95\%. It is important to note that the comprehension, grammar and vocabulary questions are objective questions and therefore the marking does not allow subjectivity.

The scores in this table clearly show that even students who pass the placement test need attention, particularly in the areas of grammar and vocabulary development. 
What does this tell us about the English skills of Kenyan students at the point of entry to the university?

1. First it clearly shows that by the time of entry to the university, the majority of students do not have adequate command of English in the various skills.

2. That the areas of grammar and vocabulary are the worst hit.

3. That even students with good high school scores may lack adequate command of the language.

\section{An Appraisal General English Courses in Kenyan Universities}

In this section I discuss the available courses in both the private and public universities that aim at providing language related skills and appraise them on the basis of the English needs observed above.

1. The various programs available in Private Universities

2. The ComSkills program in Public Universities

\section{English in the Private Universities}

The private universities have various programs aimed at getting the student grounded in language, study and communication skills. A number of them adopt the American system and provide 'Freshman's English' in two parts as a required course for all students. A number of them have an English Placement Test which helps them assess the students' language needs at the beginning of the study period. I will discuss three institutions that give an English Placement Test to determine the language needs of the students before they commence their studies.

\section{United States International University}

Every student who is admitted to the undergraduate program at United States International University is supposed to sit for the English Placement Test. The pass mark is set at $60 \%$ and students who pass this test can proceed to do the two required English courses outlined below. Those who fail the Placement Test have to take a remedial English course, and pass it with $70 \%$ and above, before they can be allowed to take the required English courses.

The remedial English course, ENG0999: Basic Reading and Writing Skills, covers summary skills, comprehension skills, vocabulary development, grammar and basic writing skills. It is a non-credit course but students who fail the placement test have to pass it in order to proceed to the required English courses.

The first of the two required English courses is basically a writing skills course. It focuses on expository writing and only touches on grammar as it relates to 
composition writing. The time and emphasis given to grammar many times depends on the person teaching the course. The second of the required English courses focuses on argumentative writing, critical reading and thinking, and the writing of research and term papers. This course has no component directly related to language structure. These courses are similar to those in institutions in the United States. Thus the assumption is that the students have adequate command of English by the time they get to the university and all the need are skills on how to structure and present academic essays. This practice does not take into account the fact that USIU is operating in an environment where the bulk of the students are users of English as a second language and thus they may need a little more English instruction than the native-speaker students.

From the analysis of the performance in the various language skills, given in tables $5 \mathrm{a}$ and $5 \mathrm{~b}$, it is clear that even those students who pass the placement test need attention in grammar and vocabulary. Thus the programs at present do not adequately address the needs of students who are users of English as a second language.

\section{Daystar University}

This institution also gives an English Placement Test. They categorize students on the basis of their English skills into four categories.

a. Applicants with grade B- in Kenya Certificate of Secondary Education (KCSE) English examination or the equivalent are exempted from the English pre-test.

b. Those with KCSE English grade lower than B- but higher than $\mathrm{D}+$, or the equivalent in other examinations are required to take the 'pre-test'. If they fail they will take a non-credit remedial English course. If they pass they join those in-group ' $a$ ' above in doing the common English courses.

c. The third group constitutes those who have KCSE English scores of $\mathrm{D}+$ and below or the equivalent in other systems. These are not subjected to the 'pre-test'. They go straight to the non-credit remedial English course.

d. Applicants from non-English speaking countries with TOEFL score of less than 500 or those without TOEFL score are required to spend the first semester studying English only.

The remedial course, ENG098 combines grammar and basic literary skills. All the students admitted to Daystar are in addition required to do two English courses as part of their General Education course whether they pass through the remedial courses or not. These courses are ENG 111: Advanced Reading and ENG112: Advanced Writing. 
The Advanced Reading focuses on reading skills, faster reading, reading comprehension and extensive reading of at least two literature texts while the Advanced Writing course basically focuses on academic writing. None of the required courses concentrates on language structure and grammar per se.

Given the statistics in tables 1 to 4 , when Daystar University exempts students with KCSE grade B- and above from the English placement test, they are exempting $71(53 \%)$ out of 133 as per the 2002 results, or 44 out of $81(54 \%)$ as per the 2003 results, of placement test failures. They are therefore allowing students who may need remedial grammar to proceed to the required courses.

\section{Africa Nazarene University}

Africa Nazarene University also has an English Placement Test but the test is optional. Students who choose not to take the English Placement Tests are automatically enrolled in the English remedial class (PUP 005) to join those who have failed the placement test. After passing PUP 005 course they join the required English classes. Those who take and pass the English Placement test proceed to the required common English courses.

There are two required English courses. The first one, UCC 101, combines grammar and writing skills and the second, UCC 102, is basically a writing course. Thus Nazarene recognizes the need for a focused English Grammar course as part of the language development of their students.

\section{Public Universities}

The only common course available that addresses students' language skills in public universities is the Comskills course, taught in one semester and covering Reading Skills, Library Skills, Speaking Skills, Study Skills and Writing Skills. The following is the description of this course as given in the Kenyatta University Calendar:

Reading skills: skimming, scanning, intensive and critical reading, interpretation of non verbal communication, content tables, indices. Listening skills: In lectures, predicting structure of a lecture, understanding gist, recognizing change of topic, following tutorial discussions.

Library skills: accessing library collections and utilizing library help services, collecting and abstracting information, note making, note taking, classification of information.

Speaking skills: in tutorials, presenting a paper, seeking clarification and explanation, giving and justifying opinions, agreeing

Writing skills: analyzing tasks, planning, drafting, editing various types of writing, quoting and paragraphing, indicating references, footnotes and bibliography. 
Study skills: planning work, organizing, storing and retrieving information, preparing for and writing examination.

This course is taught only in first year first semester. This duration is not enough to adequately cover each of the five skills listed. In fact what is listed under writing skills is extensive enough for a full semester of practical writing course. Initially classes used to have between 35 and 40 students but my enquiries during the preparation of this paper revealed that at the University of Nairobi and also at Kenyatta University, classes can have up to 100 students. In most public universities the continuous assessment is based on one comprehensive term paper/project which the students do in groups. Though the term paper is written through monitored stages, it is finished towards the end of the semester and does not provide feedback to the learners. Furthermore the number of students in a class can encourage 'joy riders' - students who benefit from the hard work of the other group members without necessarily acquiring the required skills.

\section{Findings}

The statistics based on the English placement test indicated that the areas of great need are language structure and vocabulary development. An examination of the available English courses in the Kenyan universities has revealed that, apart from Africa Nazarene University, no other university has a common English grammar course. Even though some grammar is part of one of the required English courses at USIU, the main thrust is expository writing and the time spend on language structure at times depends on the particular lecturer.

The public universities are the most wanting because what they offer under the ComSkills departments is basically general study skills which are also offered in the private universities probably under different titles (For example at USIU-A such skills are offered in a course referred to as First Year Experience) in addition to the English courses. The Comskill course puts together too many skills for the duration within which it is taught. One could argue that, since the public universities admit the 'cream' of the high school graduates, they need not have a general English course; their students can cope. However, the analysis of the results of the English placement test above showed that even students with high KSCE results failed the test. Furthermore with the growing parallel and continuing education programs the public universities are now admitting students who are of quite varied characteristics. In commenting the language needs of users of English as a second language and the need to teach language at college level, the College Composition and Communication Committee says:
Although ...linguistic support in the forms of intensive language programs and special second-language sections of writing courses may be helpful, they will not remove the responsibility of writing teachers, researchers, and administrators to address second- language issues...Second-language writers - who have come from a wide variety of linguistic, cultural, and educational backgrounds - may have special needs because the nature and functions of discourse, audience, and persuasive appeals often differ across linguistic, cultural and educational contexts. 
Furthermore, most second-language writers are still in the process of acquiring syntactic and lexical competence (College, 1)

There is no doubt that the challenges facing both undergraduate and postgraduate students in their written communication are widely discussed. Lecturers complain about the poor grammar and expressions in the students essay and yet they continue 'fishing' for the key points and giving marks for poorly written essays. Faced with the difficulties of writing in continuous coherent prose, many of our students write in point form, using either bullets or numbering. At times postgraduate students, even from language departments, require the services of an editor to get their theses into acceptable form. The questions is why is it that, while we all appreciate the challenges facing a scholar using a foreign language media, we have failed to include common English language courses at the university?

\section{Way Forward}

Since universities are not going to send students back to high school for remedial courses, after all they join university after they have passed the high school examination, the universities have a responsibility to provide courses which will give students confidence in their written work and prepare them for the challenges of writing post-graduate research in any university in the world that uses English as a medium of instruction.

We propose the following measures:

1. Give a diagnostic or placement English test given to all students admitted to a university, and provide remedial classes for those who fall below the pass mark. This is in recognition of the fact that even students with high scores at lower academic level do face significant problems when it comes writing essays at the university level. It will help the university to categorize the students and provide English instructions based on observed needs.

2. Universities need to offer at least two English courses to all the students within their first two years at the university. One of these courses should address aspects of English structure, vocabulary development and composition. This does not refer to the teaching or routine re-teaching of the parts of speech for the sake of it, but will focus on strengthening problematic areas of English grammar that inhibit the development of academic writing skills. These may include:

a. Sentence sense - fragments and run-ons

b. Coordination and subordination

c. Parallel structures

d. Dangling and misplaced modifiers

e. Pronoun reference

f. Consistency in person, case, number, tense, tone, mood and voice 
There is no doubt the majority of university students need these skills, and the universities can provide them up-front instead of letting the students grapple with the problem for four years.

\section{References}

Achebe, C. (1975). The African writer and the English language. In Morning yet on creation day. London: Heinemann.

Banda, F. (2003). A survey of literacy practices in Black and Coloured communities in South Africa: Towards pedagogy of multiliteracies. In Language, Culture and Curriculum Vol.16:2: 106 - 129

Belcher, D. and Braine, G. (eds). (1995 ) Academic Writing in a Second Language: Essays on Research and Pedagogy. Norwood, NJ: Ablex.

Braine, G. (1994). Starting ESL Classes in Freshman Writing Programs. TESOL Journal 3.4: $22-25$.

College Composition and Communication Committee. Statement on Second-Language Writing and Writers. Retrieved on $24^{\text {th }}$ October 2003 http://pubpages.unh.edu/ ppmatsuda/pubs/ ccc2001.html

Kembo-Sure (2003). Establishing A national standard and English language curriculum change in Kenya. In Language, Culture and Curriculum. Vol.16:2: 197 - 211

King'ei, K. (2002). The Role of African languages in development in the $21^{\text {st }}$ Century: Reflections on policies on African Languages in education. In Chemchemi International Journal of the School of Humanities and Social Sciences. 2 (1) 87-92

Kioko, A.N. \& Muthwii, M. J. (2001). Demands of a changing society: English in education in Kenya today. In Language, Culture and Curriculum 14 (3). 201-213

Lopez L. E. (2000). Cognition, Culture and Learning: An introduction for educational planners in multilingual and multicultural contexts. In Distance Learning Course on the Language of Instruction in Basic Education. (November $27^{\text {th }}-29^{\text {th }}$, December $1^{\text {st }} 2000$ ). 
Moyo, T. (2002). Mother tongues versus an ex-colonial language as media of instruction and the promotion of multilingualism: The South African experience.

Muthwii, M. J. (2002). Language policy and practices in education in Kenya and Uganda. Nairobi: Phoenix Publishers.

Muthwii, M. J. and Kioko, A.N. (2002). Whose English in Kenyan Secondary Schools? A case for a nativized variety. In Chemchemi International Journal of the School of Humanities and Social Sciences. 2 (1) 78-86.

Njoroge, K. (1987). The acquisition of six morpho-syntactic structures of English by Kenyan Children. Unpublished PhD thesis, University of Edinburgh.

Njoroge, M. C. (1996). Morpho-syntactic errors in the written English of first year undergraduate students in Kenya. Unpublished Masters thesis, Kenyatta University.

Nyamasyo, E. A. (1992). A corpus based study of grammatical and lexical characteristics of the writing of Kenyan pre-university students. Unpublished PhD. Thesis, University of Lancaster.

Schmied, J. (1991). English in Africa: An introduction. London: Longman

Seepe, S. (2000). A pedagogical justification for mother tongue instruction. In Seepe and Dowling (eds). The language of science. Johannesburg: Vivlia Publishers. 